\title{
AECT and ECT Internship: A Once in a Lifetime Experience for Graduate Students
}

\author{
By Ray Pastore
}

$\mathbf{T}$

he annual Association for Educational Communications and Technology 2008 convention in Orlando, FL was my first AECT convention. As this was my first AECT experience, I had yet to understand the value of the convention and the ECT internship. However, I quickly learned that being an intern gave me the opportunity to experience this convention as I had never experienced a convention before-as as an insider. The internship gave me access to board meetings and closed sessions that I would normally not have been able to attend. These meetings gave me insight into the heart of the organization and were very welcoming to me as a graduate student.

The convention itself seemed to be over in a blink of an eye, as I was very busy. I was constantly meeting new people, attending meetings, and participating in intern-only activities. For instance, each morning the interns had the opportunity to eat breakfast with senior faculty members who would provide us with valuable insight on various topics including jobs, publishing, and the future of the instructional design field. Additionally, throughout the convention we were introduced to faculty members from many universities who would discuss with us our career and research ambitions.

When the internship was completed, my intern class was invited to continue to participate in

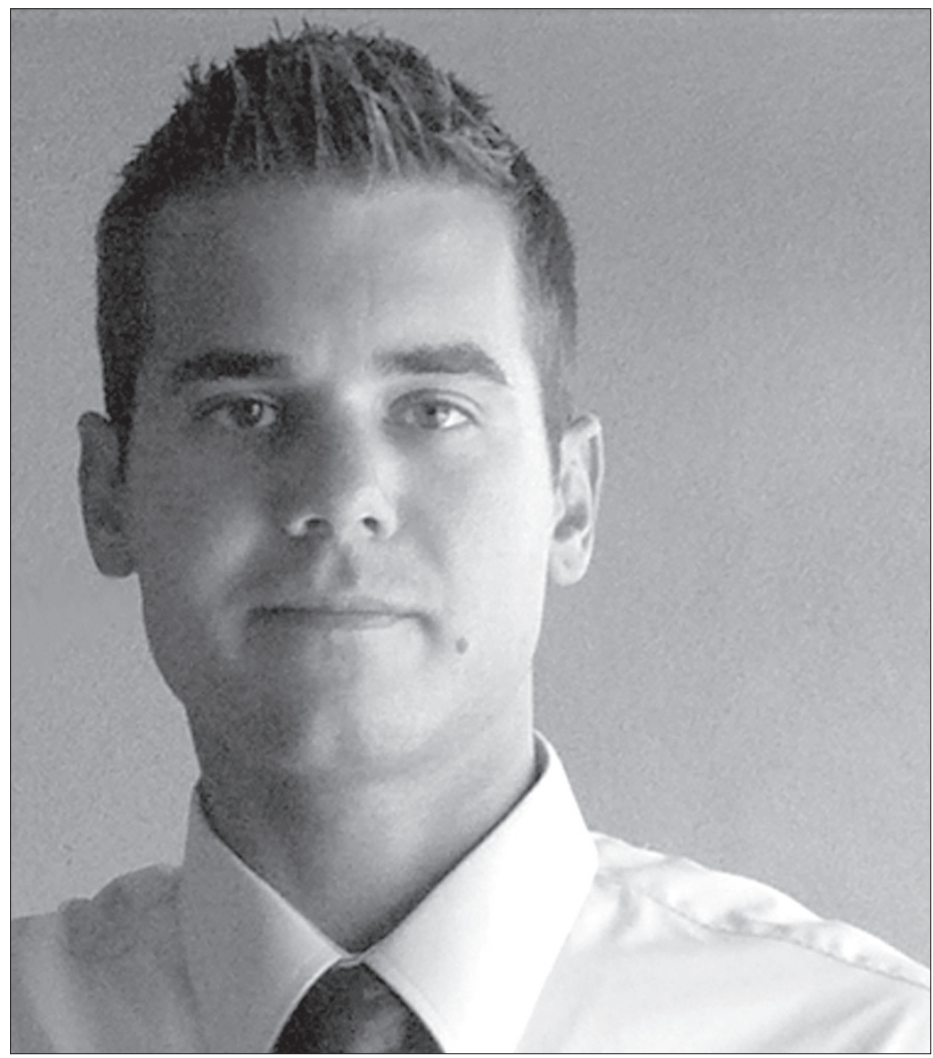

Ray Pastore

AECT. Each year the intern class is given the opportunity to contribute to the organization by working on a service project. My class is working on a mentor project; students and faculty will be paired together for a roundtable discussion during the convention. This will give graduate students a chance to meet faculty from other schools to discuss various topics and issues. It is my hope that this mentor project is continued for many years at AECT, thus being my classes' legacy.

In conclusion, the experience was great. In those few days of the convention I accomplished a great deal, which will help aid my future career as a faculty member. I made some great connections, had a great time, and learned a lot. I would encourage all graduate students to apply for the internship. It's a chance to be involved, even if it's your first AECT convention as it was mine. The experience has linked me to the organization and I hope that I can continue to participate throughout the duration of my career.

Ray Pastore has eight years of instructional design experience, which includes extensive corporate and academic experience. Ray's research focuses on multiple representations, computerbased tools, and metacognitive strategies that support learning from a multimedia environment. Ray recently completed the requirements for his Ph.D. in Instructional Systems with a minor in Educational Psychology at Penn State University and will graduate in the Summer of 2009. 